\title{
Pesquisas em ensino de arquitetura, didática de projeto e formação profissional
}

\author{
Researches in architecture teaching, project didactics and professional training \\ Investigaciones en enseñanza de la arquitectura, didáctica del proyecto y formación profesional
}

Recebido: 10/01/2022 | Revisado: 14/01/2022 | Aceito: 15/01/2022 | Publicado: 18/01/2022

\author{
Heber Macel Tenório Vasconcelos \\ ORCID: https://orcid.org/0000-0003-3555-9683 \\ Universidade Federal de Minas Gerais, Brasil \\ E-mail: bv_vasconcelos@hotmail.com \\ Marlécio Maknamara \\ ORCID: https://orcid.org/0000-0003-0424-5657 \\ Universidade Federal da Paraíba, Brasil \\ E-mail: maknamaravilhas@gmail.com
}

\begin{abstract}
Resumo
O ensino de projeto vem sendo conceituado por inúmeros pesquisadores como um processo educacional mais amplo do que a simples transmissão de técnicas e de informações. Este artigo objetiva debater questões didáticas e esboçar procedimentos para rastrear indícios da formação de profissionais arquitetos/as em contextos de ensino de projeto. A metodologia inclui analisar implicações de abordagens da Didática para o cotidiano do ensino de projeto e suas relações com a formação profissional em arquitetura. Os resultados evidenciam o argumento de que diferentes abordagens dos processos de ensino-aprendizagem disponibilizadas pelo campo da Didática têm implicações diretas sobre práticas pedagógicas em Projeto de Arquitetura. Explicitam-se limites de conceitos e de procedimentos em análises sobre relações entre a Didática e diferentes tendências para o ensino de projeto. $\mathrm{O}$ artigo conclui ressaltando que essa reflexão estimula as bases preliminares para um objeto em construção, articulando pesquisas em ensino de arquitetura, didática de projeto e formação profissional de futuros arquitetos/as.
\end{abstract}

Palavras-chave: Didática; Ensino de arquitetura; Formação profissional.

\begin{abstract}
The project teaching has been conceptualized by numerous researchers as an educational process that is broader than the simple transmission of techniques and information. This article aims to debate didactic issues and outline procedures to track evidence of the formation of professional architects in project teaching contexts. The methodology includes analyzing implications of Didactics approaches for the daily project teaching and its relationship with professional training in architecture. The results show the argument that different approaches to teaching-learning processes provided by the field of Didactics have direct implications for pedagogical practices in Architectural Project. Limits of concepts and procedures are explained in the analysis of the relationship between Didactics and different trends in project teaching. The article concludes by emphasizing that this reflection stimulates the preliminary bases for an object under construction, articulating research in architecture education, project didactics and professional training for future architects.
\end{abstract}

Keywords: Didactics; Architecture teaching; Professional training.

\section{Resumen}

La enseñanza del proyecto ha sido conceptualizada por numerosos investigadores como un proceso educativo más amplio que la simple transmisión de técnicas e información. Este artículo tiene como objetivo debatir cuestiones didácticas y esbozar procedimientos para rastrear la evidencia de la formación de arquitectos profesionales en contextos de enseñanza del proyecto. La metodología incluye analizar las implicaciones de los enfoques didácticos para la enseñanza diaria del proyecto arquitectónico y su relación con la formación profesional en arquitectura. Los resultados muestran el argumento de que los diferentes enfoques de los procesos de enseñanza-aprendizaje proporcionados por el campo de la Didáctica tienen implicaciones directas para las prácticas pedagógicas en el Proyecto Arquitectónico. Los límites de conceptos y procedimientos se explican en el análisis de la relación entre la Didáctica y las diferentes tendencias en la enseñanza del proyecto. El artículo concluye destacando que esta reflexión estimula las bases preliminares de un objeto en construcción, articulando la investigación en la enseñanza de la arquitectura, la didáctica del proyecto y la formación profesional de los futuros arquitectos.

Palabras clave: Didáctica; Enseñanza de la arquitectura; Formación profesional.

\section{Introdução}

Partidos, conceitos, desenhos, esboços, composições, formas, funções, cores, matizes, expressividades, técnicas, 
perspectivas, escalas, sensibilidades, habilidades, procedimentos, atitudes, funcionalidades, setorizações, materiais, repertórios, estéticas, tendências históricas... Estes são alguns dos termos que compõem o ensino de projeto de arquitetura.

O Ensino de projeto vem sendo conceituado por inúmeros pesquisadores como um processo educacional mais amplo do que a simples transmissão de técnicas e de informações ou de treinamento para o exercício da profissão de arquiteto e urbanista (Teixeira, 2005; Barossi, 2005; Domschke, 2008; Batlle, 2011). Mas como o ensino de projeto de arquitetura tem figurado nas pesquisas da área? Que alcances e limites tais pesquisas apontam para a formação de arquitetos/as? Quem é o/a arquiteto/a que emerge das linguagens utilizadas para falar de ensino de projeto nas pesquisas em ensino de arquitetura, afinal? O que tem sido entendido por didática em projeto de arquitetura, afinal?

Os questionamentos supracitados são fundamentais a um conhecimento mais aprofundado acerca dos estilos e tendências de ensino e, sobretudo, das perspectivas de formação de sujeitos arquitetos a partir do ensino de projeto que lhes é oferecido. Eles vinculam-se a uma pesquisa mais ampla, em nível de doutorado, cuja proposta é analisar como aspectos didáticos desdobram-se na constituição do sujeito arquiteto a partir das linguagens da didática de projeto nas pesquisas em ensino de arquitetura. No presente artigo, o objetivo é debater questões didáticas e esboçar procedimentos para rastrear indícios da formação de profissionais arquitetos/as em contextos de ensino de Projeto.

\section{Contextualização e Horizonte Teórico}

No Brasil, o interesse em analisar questões relacionadas ao ensino de projeto de arquitetura tem crescido nas últimas décadas (Vidigal, 2010). Se "a reflexão sobre ensino de arquitetura e urbanismo pode ser feita sob diferentes aspectos" (Teixeira, 2005), o aspecto didático pode ser uma das chaves de entrada nesse debate do ensino de projeto. Discutir aspectos didáticos relacionados às disciplinas de projeto de arquitetura é fundamental, pois essas disciplinas, "além de indispensáveis, absorvem parte significativa da disponibilidade temporal e emocional dos estudantes durante a graduação e representam percentual de horas alto dentro da carga horária do curso" (Quevedo \& Keuchkarian, 2020).

A Didática é o campo educacional que estuda os processos de ensino-aprendizagem (Libaneo, 1994). Ao interessar-se por tais processos, ela aborda o ensinar e o aprender focalizando diferentes aspectos daquilo que constitui o cerne do que se passa em sala de aula. No Brasil, esse campo ganhou notoriedade e visão crítica sobre os processos de ensino-aprendizagem a partir dos anos 1980 (Damis, 2004). Desde então, são múltiplos os temas, objetos e questões que interessam a quem se dedica a esse campo de estudos. Ao longo de seu desenvolvimento, a Didática tem advogado que se deve primar por abordar o ensino tendo em vista sua multidimensionalidade (Candau, 2012; Mizukami, 1986).

O campo da Didática tem insistido que todo ensino possui pelo menos três dimensões: técnica, política e humana. A dimensão técnica diz respeito aos procedimentos próprios do conteúdo a ser ensinado: "aspectos como objetivos instrucionais, seleção de conteúdo, estratégias de ensino, avaliação etc, constituem o seu núcleo de preocupações. Trata-se do quesito considerado objetivo e racional dos processos de ensino e aprendizagem" (Candau, 2012, p. 15). A dimensão política explicitada pela Didática diz respeito às relações entre o que se ensina e os efeitos sobre as relações que os indivíduos estabelecem entre si na sociedade: "se todo o processo de ensino-aprendizagem é 'situado', a dimensão político-social lhe é inerente. Ele acontece sempre em uma cultura específica, envolve pessoas concretas que têm uma posição de classe definida na organização social em que vivem” (Candau, 2012, p. 15). Já a dimensão humana, por sua vez, para essa mesma autora, compreende os aspectos subjetivos, afetivos e emocionais que atravessam as inter-relações pessoais na realização do ensinar.

A identificação das múltiplas dimensões de ensino auxilia na compreensão daquilo que orienta o fazer, em sala de aula, em prol da aprendizagem. Contudo, os processos de ensinar e aprender tornam-se ainda mais complexos quando se tem conhecimento da variedade de abordagens que é possível conferir à orientação do trabalho do professor. Algumas classificações - ora de maneira mais direta, ora mais indiretamente - têm sido feitas sobre as diferentes formas de abordar o 
processo de ensino-aprendizagem a partir das reflexões da Didática. Libâneo (1987) e Mizukami (1986) podem ser apontados como aqueles cujas obras têm servido, de maneira mais freqüente, como referência para o entendimento da temática em questão. Deve-se lembrar, entretanto, que tais classificações nunca tiveram a pretensão de se apresentar como "leis invariáveis" sobre o processo de ensino-aprendizagem: servem para auxiliar a compreensão desse processo, reconhecendo que dentro da dinamicidade das práticas docentes é possível perceber, em alguns momentos, a presença concomitante de elementos dispostos em diferentes grupos destas classificações).

\section{Metodologia: Esboço de Procedimentos Metodológicos para Acessar o Material Empírico}

Para atender ao foco e ao objetivo da pesquisa aqui em tela, a metodologia será operacionalizada mediante mapeamento das dimensões, abordagens e demais elementos de ensino de projeto de arquitetura, privilegiando procedimentos da Cartografia, com base em Deleuze e Guattari, para compreender como as linguagens das pesquisas em ensino de Projeto desdobram-se na constituição de sujeitos arquitetos. A pesquisa insere-se na vertente qualitativa. Para esse tipo de abordagem o que realmente importa é qualidade do estudo, da análise e da pesquisa e não dos seus possíveis números, equações e resultados (Gerhardt \& Silveira, 2009).

Quem assume a abordagem qualitativa se opõe e se recusa ao modelo positivista para a realização de estudos voltados à vida e às relações sociais. O pesquisador assume que seu conhecimento sobre o objeto e os sujeitos são parciais e limitados. Dessa forma, o objetivo de uma pesquisa qualitativa é produzir informações aprofundadas e ilustrativas, importando apenas que seja capaz de gerar novos conhecimentos e informações (Deslauriers apud Gerhardt \& Silveira, 2009). O universo de estudo da pesquisa diz respeito à linguagem da didática de projeto nas pesquisas em ensino de arquitetura. $\mathrm{O}$ foco da pesquisa recairá sobre os estilos e as tendências de ensino presentes na produção acadêmica nacional em didática de projeto para chegar ao problema da formação de sujeitos arquitetos.

Para o mapeamento das dimensões, abordagens e demais elementos de ensino de projeto de arquitetura, a abordagem terá inspiração pós-crítica, privilegiado os procedimentos da Cartografia. A ideia de cartografia aqui adotada, além de ter inspirações em seus postuladores - Deleuze e Guattari -, foi depreendida de Passos et al. (2009) e de Rolnik (2006). Com base em tais obras, três pistas cartográficas foram entendidas como mais adequadas para se alcançar os objetivos pretendidos: a cartografia como método de acompanhar processos, a cartografia como pesquisa/análise-intervenção e a cartografia como política de uma narratividade.

A primeira pista cartográfica para acessar o material empírico diz respeito ao método de acompanhar processos. Pozzana e Kastrup (2009) alertam que a expressão "investigação de processos" possui dois sentidos diferentes. O primeiro sentido, ligado à teoria da informação, representa a pesquisa que é praticada como coleta e análise de informações, não sendo este o entendimento reconhecido pelo pesquisador cartógrafo. O processo para o cartografo é entendido como processualidade, sendo esse o coração da cartografia (Pozzana \& Kastrup, 2009). A pesquisa focada na investigação de processos faz o cartógrafo deparar-se com a necessidade de começar pelo meio. Isso ocorre por vários motivos, dentre os quais: pelo momento presente já carregar uma história e pelo território presente possuir uma espessura processual (Pozzana \& Kastrup, 2009).

Muitas pesquisas costumam seguir uma mesma sequência de etapas - coleta, análise e discussão de dados. Esse modo representa uma série de momentos distintos e separados entre si, de modo que apenas quando se termina uma etapa se prossegue para a próxima. Ao contrário, a cartografia se constitui de etapas que podem ou não ser sequenciais, porém que não se separam (Pozzana \& Kastrup, 2009). Dessa forma, a cartografia pode ser entendida "como o próprio ato de caminhar, onde um passo segue o outro num movimento contínuo, cada momento da pesquisa traz consigo o anterior e se prolonga nos momentos seguintes" (Pozzana \& Kastrup, 2009, p. 59).

Ao acompanhar um processo, torna-se possível desenhar as redes e as conexões de forças às quais o objeto está 
ligado, possibilitando a compreensão do seu papel e do seu nível de influência e de participação no processo investigado (Pozzana \& Kastrup, 2009). Para que o processo seja acompanhado de modo livre, Pozzana e Kastrup (2009) afirmam que é necessário deixar-se levar pelo campo coletivo de forças. O objetivo do deixar-se levar é evitar a busca por informações, dados e comprovações, para que o foco recaia e seja direcionado na possibilidade de o cartógrafo abrir-se ao encontro com o novo. Como é possível compreender a partir e Rolnik (2007), o que se espera do cartógrafo é uma imersão nas intensidades para que seja dada voz aos "afetos que pedem passagem". Colocar em prática a possibilidade de aceitar o devir ao acompanhar o processo, nem sempre é fácil, por exigir prática e por não poder ser aprendido através de livros (Pozzana \& Kastrup, 2009).

A segunda pista cartográfica de aproximação ao objeto da pesquisa, com base em Passos e Barros (2009a), diz que a cartografia pode ser adotada como método de pesquisa/análise-intervenção. Todavia, é importante destacar que apesar do método cartográfico não ser constituído por regras predefinidas a serem seguidas ou por objetivos pré-estabelecidos, esses fatos não são suficientes para entendê-lo como uma ação sem direção ou sem rumo. Mesmo que a cartografia modifique o sentido tradicional de método, ela não é realizada sem orientação, sem as pistas necessárias para a realização do percurso e da pesquisa.

A compreensão da cartografia como pesquisa-intervenção fica mais clara quando percebemos que é impossível separarmos o conhecer do fazer, o pesquisar do intervir. Nesse sentido, Passos e Barros (2009a) apontam que devemos não apenas nos aproximarmos dos objetos que investigamos, mas nos tornarmos parte deles. Consideram que objeto, sujeito e conhecimento são efeitos coemergentes do processo de pesquisar, que a pesquisa cartográfica não pode se apoiar no que já se sabe, mas, sim, em um saber que vem e surge do fazer, que propõe transformar para conhecer e nega o conhecer para transformar (Passos \& Barros, 2009a).

A pesquisa-intervenção busca dar luz aos processos, ao que ocorre, ao que se constitui nas relações sociais e a tudo que possui potência (Passos \& Barros, 2009a). Tal tipo de pesquisa desconstrói a noção de campo, uma vez que modifica seus limites e suas configurações (Passos \& Barros, 2009a). Lourau (apud Passos \& Barros, 2009a) define "campo de intervenção" conforme sua metaestabilidade, ou seja, de acordo com as oposições que nele se apresentam sujeito e objeto, local e global, indivíduo e grupo. Estas oposições Lourau (apud Passos \& Barros, 2009a) denominou de dinâmicas transductivas ou dinâmicas de devir, que segundo o autor "potencializam resistências atuais e atualizam existências potenciais" (Lourau apud Passos \& Barros, 2009a). É a partir desse momento que o conceito de "implicação" passa a ser revisto, diante do conceito de "transduç̧ão", o que acabou por radicalizar a crítica à neutralidade e ao objetivismo científico.

Chegar ao conhecimento, implica, dessa forma em criar uma nova realidade do observador, do objeto e do mundo. Essa ação também se constitui como um ato e/ou posicionamento político, portanto trata-se de intervir na realidade enquanto a mesma é pesquisada. Passos e Barros (2009a, p. 17) afirmam que "tal processo se dá por uma dinâmica de propagação da força potencial que certos fragmentos da realidade trazem consigo. Propagar é ampliar a força desses germens potenciais numa desestabilização do padrão". Isso torna ainda mais evidente a importância de acompanhar processos por meio da imersão no plano da experiência, pois apenas quando se assume que o conhecimento sempre representa uma transformação da realidade é que a pesquisa pode ganhar complexidade e assim se tornar capaz de explorar os limites dos procedimentos metodológicos utilizados (Passos \& Barros, 2009a). Então, para a presente pesquisa, conhecer o caminho será equivalente a "caminhar com esse objeto, constituir esse próprio caminhar, constituir-se no caminho. Esse é o caminho da pesquisa-intervenção" (Passos \& Barros, 2009a, p.17).

A terceira pista cartográfica compreende uma política da narratividade. Para dar início a esta última pista é importante destacar a seguinte frase: "Somente a expressão nos dá o procedimento" (Deleuze \& Guattari apud Passos \& Barros, 2009b). A escolha de uma determinada posição narrativa deve ser entendida como algo conectado às políticas que representam a pesquisa. Desse modo, não podemos abrir mão de uma linguagem própria para nos fazer entender (Passos \& Barros, 2009b). A 
política da narratividade se apresenta como uma posição tomada pelo pesquisador, frente ao mundo e a si mesmo, definindo sua forma de expressar o que acontece e o que percebe/enxerga em seu percurso (Passos \& Barros, 2009b). Logo, a cartografia nos permite explorar outras formas de escrita, admitindo um sentido diferente para rigor metodológico. Isso amplia possibilidades de expressão, sem que haja um comprometimento do exercício crítico exigido por qualquer pesquisa, assim permitindo a criação de uma escrita própria sobre a didática de projeto nas pesquisas em ensino de arquitetura.

A partir da argumentação desenvolvida anteriormente, é possível compreender que quem opta pelo método da cartografia, além de realizar uma pesquisa-intervenção, acaba por assumir um posicionamento político. Desse modo, a forma de relação com o material empírico assumida e entendida como a mais apropriada será do tipo "rizomática", ou seja: aberta, difusa, indeterminada e não-hierárquica. O termo "rizoma", originalmente conceituado e adotado pelas ciências biológicas, foi apropriado por Deleuze e Guattari, em oposição ao modelo positivista de árvore (Deleuze \& Guattari, 2011a). O modelo rizomático é representado por linhas e não por formas, de modo a permitir que o que seja pesquisado/investigado/analisado possa "fugir, se esconder, confundir, sabotar, cortar caminho" (Trindade, 2013). Essas linhas denominadas por Deleuze \& Guattari (2011a) como "linhas de fuga" representam linha de intensidades. São chamadas dessa forma por buscarem fugir de tentativas totalizantes. Desse modo, o modelo rizomático apresenta-se como uma resistência ética, estética e política ao pensamento cartesiano, positivista e linear ainda vigente em formas de pesquisar e ensinar em Arquitetura.

\section{Resultados e Discussão: Didática e o Ensino de Projeto de Arquitetura - Elementos para um Objeto em Construção}

É sabido que "o ensino de projeto nos cursos de Arquitetura se realiza por meio de diferentes teorias e métodos, que podem orientar, ensinar, subsidiar os processos de criação" (Masseran et al., 2015, p. 106). Mas que tipos de contrapartidas a Didática do Projeto de Arquitetura pode obter a partir das reflexões da Didática em torno da multidimensionalidade do ensinar e das várias abordagens dos processos de ensinar e aprender?

Libâneo (1990), na obra "Democratização da Escola Pública", elenca diretamente três possíveis abordagens ("enfoques", nas palavras daquele autor) da Didática frente ao processo de ensino-aprendizagem em diferentes tendências pedagógicas. Para ele, existiriam a Didática Tradicional, a Didática Renovado-Tecnicista e a Didática Sociopolítica. A Didática Tradicional se constituiria (e ainda se constitui, uma vez que diz respeito às orientações tradicionais da prática docente, as quais ainda persistem no cenário educacional brasileiro) como legítimo campo de prescrições tradicionalistas sobre como configurar uma prática docente com vistas à concretização de uma tendência tradicional de ensino, dentro de uma pedagogia liberal. Por outro lado, a Didática Renovado-Tecnicista incorporaria elementos tanto da Escola Nova (pedagogia ativa, ênfase nos processos mentais e na solução de problemas pelos alunos) quanto da tendência tecnicista da pedagogia liberal (sendo esta tal tendência presente pela ênfase na tecnologia educacional, na instrução programada e na produtividade tecnicista do trabalho docente).

Tais restrições analíticas da Didática sobre a prática docente seriam o alvo da crítica orientadora da Didática Sociopolítica. Esta se caracterizaria como uma abordagem da Didática que privilegiaria o reconhecimento das implicações sociais mais amplas sobre a escola e a prática pedagógica dos professores. Abrigaria tanto as tendências libertadora e libertária quanto os pressupostos da tendência pedagógica crítico-social dos conteúdos. Enquanto as tendências libertadora e libertária conceberiam a prática docente como um momento de denúncia e instrumento de luta política - cujo extremo implicou, no passado, na própria negação da Didática - através de vivências voltadas à vida grupal, crítica das relações sociais e participação política, a tendência crítico-social dos conteúdos entenderia que a prática docente é um (ou deve ser) instrumento de luta política, mas sem abandonar a especificidade pedagógica do processo de ensino-aprendizagem.

As implicações destas diferentes abordagens da Didática, especificamente sobre a prática pedagógica em ensino de 
projeto, são sintetizadas a seguir:

- Didática Tradicional: valoriza o aspecto material do ensino - no sentido da mera transmissão de informações -, considerando que a prática docente em ensino de Projeto dependeria unicamente dos ditames do professor (uma vez que ele é tido como centro do processo de ensino-aprendizagem e considerado como o único detentor do saber), ao qual se atribui o total controle do ato de ensino, que por sua vez é pautado na transferência de informações;

- Didática Renovado-Tecnicista: ao inspirar o ensino de Projeto e os problemas inerentes à prática profissional de arquitetos/as como elementos para serem analisados restritamente - dentro da perspectiva interna da prancheta, do escritório e da relação profissional-cliente -, ela superestima tanto o valor e a eficiência de habilidades técnicas ao se ensinar Projeto quanto os "modelos" universais de profissional;

- Didática Sociopolítica: sugere que a melhor maneira de formar arquitetos/as seria fornecer-lhes criticamente os conteúdos de Projeto de que necessitam de modo a se situarem no mundo para, bem situada e localizada a prática profissional, poder através dela ajudar a transformar sua realidade. Desta forma, considera que o ensino de Projeto e a prática profissional em arquitetura devem nortear-se pela indissociabilidade entre Projeto e sua significação individual e coletiva.

Mizukami (1986), por sua vez, classificou em cinco diferentes abordagens as possibilidades de encaminhamento didático dos processos de ensino-aprendizagem. Para essa autora, as abordagens que orientam o processo de ensinoaprendizagem podem ser: tradicionalista, comportamentalista, cognitivista, humanista e sociocultural. Acompanhando as ideias de Mizukami (1986), pode-se fazer um exercício de apropriação para se pensar como as abordagens de ensino podem se revelar na formação do arquiteto e, particularmente, no âmbito da didática do projeto de arquitetura:

- Abordagem tradicionalista: poderia ser encontrada quando o professor optasse por assumir um protagonismo e um papel hierárquico. $\mathrm{O}$ ensino tradicionalista seria, portanto, aquele em que apenas apresentariam conteúdos, sem nenhum tipo de troca - como corta e dobrar o papel, como utilizar os instrumentos, como aproveitar mais os espaços, como maximizar o potencial dos projetos etc. -, cabendo aos alunos apenas reter e acumular tais informações;

- Abordagem comportamentalista: em aulas de projetos de arquitetura, compreenderia aos professores que utilizam técnicas didáticas focadas no aprendizado por meio de recursos reconhecido como necessários para gerar um determinado comportamento - quanto mais praticar na prancheta melhor se tornará o traço, quanto mais assistir a filmes de arte mais se tornará um arquiteto sensível, quanto mais estudar plantas mais irá realizar projetos funcionais, quanto mais praticar calculo mais conseguirá projetar obras com estruturas mais ousadas - , o professor que opera dessa forma, portanto, entende que o conhecimento é realizando quando o comportamento do aluno foi modificado em função da prática e da repetição;

- Abordagem humanista: encontrar-se-ia em aulas de projeto focadas na evolução dos alunos, da sua autonomia, confiança e personalidade - aulas de projeto que respeitem e considerem as ideias, singularidades, sensibilidades, tempo e processo de cada aluno. O professor humanista trabalha e age como um facilitador do desenvolvimento pessoal, pois entende que o aluno-individuo é único e, por isso, deve encontrar seu próprio caminho;

- Abordagem cognitivista: representa professores de projeto que adotam experiências desafiadoras mediante conflitos cognitivos com a finalidade de promover a desestabilização do que já está dado - solicitando projetos mais complexos ou que não estavam previstos, quando propõe que se encontrem soluções projetuais em um tempo curto, quando exigem a utilização de novas técnicas/materiais/tecnologias - permitindo o desenvolvimento do aluno a partir da sua própria inteligência e cognição;

- Abordagem sociocultural: em aulas de projeto de arquitetura, seria aquela em que o docente se posiciona de forma horizontal, ou seja, sem hierarquia, mas, mais que isso, que busca inserir reflexões críticas, políticas e culturais. Os professores que assumem esse tipo de abordagem possibilitam discussões que se interessam por aspectos sociais/culturais da comunidade de que fazem parte - seriam projetos que visariam pensar na dimensão social que cada conteúdo traz, como por exemplo, uso 
de recursos e de materiais mais eficientes e menos nocivos ao meio ambiente, de matérias primas próprias do lugar, de usar elementos próprios da cultura em seus projetos etc.

Toda essa discussão, centrada em aspectos didáticos, contribui "para ampliar a visão do professor quanto às perspectivas didático-pedagógicas mais coerentes com nossa realidade educacional, ao analisar as contradições entre o que é realmente o cotidiano da sala de aula e o ideário pedagógico" (Veiga, 2004, p. 44). Também revela estilos e tendências de ensino em arquitetura. Várias pesquisas chegaram a apontar diretrizes, soluções e caminhos no sentido de garantir uma melhor didática de ensino de projeto (Ronconi, 2002; Brandão, 2008; Petrini \& Bortolli Jr., 2017). Outras, por sua vez, realizaram análises de currículos ou de planos de curso (Teixeira, 2005; Breia, 2006). E outra pequena minoria buscou implicar as duas vertentes anteriores (Naruto, 2006; Vidigal, 2010).

No entanto, nenhuma dessas três frentes investigativas propôs-se a pesquisar o ensino de tal forma a compreender como aspectos didáticos desdobram-se na constituição do sujeito arquiteto. Até mesmo relações entre arquitetura e produção de sujeitos, tomando-se a arquitetura como projeto de subjetivação, não têm sido frequentes nas pesquisas que articulam arquitetura e educação no Brasil (Vasconcelos \& Maknamara, 2020). Se é considerado "importante que os cursos de PósGraduação na área da Arquitetura e Urbanismo reservem espaços maiores para a discussão de questões fundamentais como didática e técnicas para o ensino de projeto arquitetônico" (Nogueira, 2009, p. 160); se "pensar sobre o ensino de projeto requer a utilização de procedimentos, conceitos e objetivos próprios da produção da arquitetura" (Barossi, 2005, p.2); se "o ensino para projeto de arquitetura encontra limites também em sua capacidade de formular regras e métodos que garantam o sucesso" (Kotchetkoff, 2016, p. 292) e o resultado final do saber-fazer oriundo do ensino de projeto "sempre necessitará de escolhas do arquiteto, e sempre será dirigido por sua personalidade e seu conhecimento" (Kotchetkoff, 2016, p. 289); e se há conexões entre procedimentos projetuais, docência e modo de ser arquiteto (Iuwamizu, 2015), constitui um objeto inédito e original para o campo da arquitetura e do urbanismo aarticular pesquisas em ensino de arquitetura, didática de projeto e formação de futuros arquitetos/as.

Mas como as pesquisas em ensino de arquitetura poderiam lidar com tal discussão? Ou seja, como tais dimensões e abordagens de ensino figuram nas pesquisas em ensino de arquitetura focadas na didática de projeto? Quais as linguagens utilizadas para falar de ensino nessas pesquisas? O que, afinal, faz gaguejar a linguagem da didática de projeto nas pesquisas em ensino de arquitetura? A hipótese lançada na pesquisa à qual este artigo se vincula é a de que a linguagem da didática de projeto nas pesquisas em ensino de arquitetura pode revelar não apenas estilos e tendências de ensino, mas, sobretudo, perspectivas de formação de sujeitos arquitetos. Afinal, qual é o tipo de sujeito possível, quem é o arquiteto que emerge das linguagens utilizadas para falar de ensino de projeto nas pesquisas em ensino de arquitetura? A seguir, são explicitadas as bases metodológicas em que esse tipo de pesquisa se faz possível.

\section{Considerações Finais}

Este artigo objetivou debater questões didáticas e esboçar procedimentos para rastrear indícios da formação de profissionais arquitetos/as em contextos de ensino de projeto. Possibilidades de articulação entre pesquisas em ensino de arquitetura, didática de projeto e formação profissional de futuros arquitetos/as ensejam a hipótese de que a linguagem da didática de projeto nas pesquisas em ensino de arquitetura pode revelar não apenas estilos e tendências de ensino, mas, sobretudo, perspectivas de formação de sujeitos arquitetos. No sentido de contribuição para tal debate, vale destacar o papel da Didática, considerando que toda abordagem a partir da qual ela é concebida conduz a uma determinada prática pedagógica, seja pela tendência em simplesmente prescrever "como ensinar", seja pela tendência em fundamentar uma reflexão que possibilite a formação de arquitetos/as que sejam capazes de decidir o "como projetar" de maneira associada ao "por quê" e "para quem" projetar. 
As maneiras como práticas pedagógicas em ensino de Projeto de Arquitetura são engendradas em cursos de formação de arquitetos/as constitui fator primordial na configuração de possibilidades de colaboração na superação ou manutenção de problemas internos e externos à profissão. Isso também porque práticas pedagógicas em arquitetura (como em qualquer outra área profissional) não apenas informam, mas conformam: se elas ativam e estimulam sensações, favorecem percepções, difundem valores, proporcionam aprendizagens, dotam indivíduos de habilidades e capacidades, estão diretamente implicadas com a produção de sujeitos. Portanto, abordagens didáticas em ensino de Projeto concorrem para processos de subjetivação, participam ativamente da produção de modos de ser e de estar na profissão de arquiteto/a, demandam, disponibilizam e incitam tipos de sujeitos arquitetos, têm centralidade na produção de possíveis em Arquitetura.

Nesse sentido, é relevante e produtivo prosseguir com a pesquisa aqui esboçada, no sentido de ampliar o já estabelecido nas linguagens utilizadas para falar do ensino de projeto e visibilizar seus efeitos na produção de arquitetos. Na sequência dos primeiros resultados aqui apresentados, o foco da pesquisa recairá sobre estilos e tendências de ensino e construções curriculares para se chegar ao problema da formação de sujeitos arquitetos. Espera-se, com esse esquadrinhamento, visibilizar dimensões das articulações entre arquitetura e educação que avancem em relação aos já conhecidos três eixos de sentidos prevalentes em pesquisas brasileiras que conectam arquitetura e educação (arquitetura escolar como projeto social, arquitetura escolar como projeto didático, arquitetura escolar como projeto de subjetivação), conforme identificados por Vasconcelos e Maknamara (2020). Isso significa abertura para problematização dessas relações entre arquitetura e educação em termos dos efeitos de estilos e tendências de Ensino de Arquitetura (notadamente, ensino de Projeto) sobre possibilidades de formação e de atuação profissional de arquitetos/as.

\section{Agradecimentos}

Agradecemos à CAPES a Bolsa de Demanda Social concedida a um dos autores deste artigo.

\section{Referências}

Barossi, A. C. (2005). Ensino de projeto na FAUUSP: Faculdade de Arquitetura e Urbanismo da Universidade de São Paulo. 462f. Tese de Doutorado. Universidade de São Paulo, São Paulo.

Barros, L. P. \& Kastrup, V. (2009). Cartografar é acompanhar processos. Passos, E.; Kastrup, V. \& Escóssia, L. (Orgs.). In: Pistas do método da cartografia: Pesquisa-intervenção e produção de subjetividade. Porto Alegre: Sulina, p. 52-75.

Batlle, A. O. (2011). O papel do desenho na formação e no exercício profissional do arquiteto-conceitos e experiências. 202f. Tese de Doutorado. Universidade de São Paulo, São Paulo.

Brandão, O. C. S. (2008). Sobre o fazer projeto e aprender a fazer projeto. 272f. Tese de Doutorado. Universidade de São Paulo, São Paulo.

Breia, M. T. S. (2006). A transição do ensino da arquitetura Beaux-Arts para o ensino da arquitetura moderna na Faculdade de Arquitetura Mackenzie 1947-1965. 2006. 488 f. Tese de Doutorado. Universidade de São Paulo, São Paulo.

Candau, V. M. (2012). A didática e a formação de educadores - Da exaltação à negação: a busca da relevância. In Candau, V. M. (Org.). A Didática em questão. (33a ed.), Vozes, 13-24.

Corazza, S. (2001). O que faz gaguejar a linguagem da escola. In: Candau, V. M. (Org.). Linguagens, espaços e tempos no ensinar e aprender. (2a ed.), DP\&A, 89-103.

Corazza, S. \& Silva, T. T. (2003). Composições. Autêntica.

Damis, O. T. (2004). Didática: suas relações, seus pressupostos. In: Veiga, I. P. A. (Org.). Repensando a Didática. (4a ed.), Papirus, 13-32.

Domschke, V. L. (2008). O ensino da arquitetura e a construção da modernidade. 331f. Tese de Doutorado. $311 \mathrm{f}$. Dissertação de Mestrado. Universidade de São Paulo, São Paulo.

Iwamizu, C. S. (2015). Eduardo de Almeida: reflexões sobre estratégias de projeto e ensino. 546f. Tese de Doutorado. Universidade de São Paulo.

Kotchetkoff, J. C. (2016). Limites e possibilidades no ensino de projeto de arquitetura. Universidade de São Paulo.

Libâneo, J. C. (1994). Didática. Cortez. 
Research, Society and Development, v. 11, n. 2, e4911225563, 2022

(CC BY 4.0) | ISSN 2525-3409 | DOI: http://dx.doi.org/10.33448/rsd-v11i2.25563

Mizukami, M. G. N. (1986). Ensino: as abordagens do processo. EPU.

Masseran, P.; Salcedo, R. F. B.; Gomes, S.; Amaral, C. (2015). Teorias e métodos aplicados ao ensino do projeto de arquitetura: curso de Arquitetura e Urbanismo da FAAC-UNESP. In: Fiorin, E.; Landim, P. C.; Leote, R. S. (Orgs.). Arte-ciência: processos criativos. São Paulo: Cultura Acadêmica, p. 97-130.

Naruto, M. (2006). Repensar a formação do arquiteto. 130f. Tese de Doutorado. Faculdade de São Paulo.

Nogueira, M. L. (2009). Ensino de projeto no primeiro ano e suas abordagens. 170f. Tese de Doutorado. Universidade de São Paulo.

Veiga, I. P. A. (2004). Didática: uma retrospectiva histórica. In: Veiga, I. P. A. (Org.). Repensando a Didática. (4a ed.), Papirus, 33-54.

Vidigal, E. J. (2010). Ensino de projeto arquitetônico: um estudo sobre as práticas didáticas no curso de arquitetura e urbanismo da Universidade Federal do Paraná. 330f.Tese de Doutorado. Universidade de São Paulo, São Paulo.

Paraíso, M. (2021). Metodologias de pesquisas pós-críticas em educação e currículo: trajetórias, pressupostos, procedimentos e estratégias analíticas. In: Paraíso, M. \& Meyer, D. E. E. (Orgs.). Metodologias de pesquisas pós-críticas em educação. Mazza, 25-47.

Passos, E. \& Barros, R. B. (2009a). A cartografia como método de pesquisa-intervenção. In: Pistas do método da cartografia: Pesquisa-intervenção e produção de subjetividade. Sulina, p. 17-31.

Passos, E. \& Barros, R. B. (2009b). Por uma política da narratividade. Passos, E.; Kastrup, V. \& Escóssia, L. (Orgs.). In: Pistas do método da cartografia: Pesquisa-intervenção e produção de subjetividade. Sulina, 150-171.

Petrini, L. S. (2017). Considerações sobre o ensino de Arquitetura e Urbanismo no modo de produção capitalista no estado de São Paulo. 122f. Dissertação de mestrado. Universidade de São Paulo, São Paulo.

Quevedo, C. \& Keuchkarian, D. A. (2020). Disciplina de projeto de arquitetura: a atualidade e a perspectiva fenomenológica. Arquitextos, 239 (05), https://vitruvius.com.br/revistas/read/arquitextos/20.239/7674

Ronconi, R. L. N. \& Ghoubar, K. (2002). Inserção do canteiro experimental nas Faculdades de Arquitetura e Urbanismo. 316f. Tese de Doutorado. Universidade de São Paulo, São Paulo.

Silva, T. T. (2010). Documentos de Identidade: Uma Introdução às Teorias de Currículo. (3a ed.), Editora Autêntica.

Teixeira, K. A. (2005). Ensino de projeto: integração de conteúdos. 237f. Tese de Doutorado. Universidade de São Paulo.

Vasconcelos, H. \& Maknamara, M. (2020). Arquitetura e Educação: arquitetura escolar como elemento dos espaços escolares. Research, Society and Development, 9 (7), e106973986, 10.33448/rsd-v9i7.3986. https://rsdjournal.org/index.php/rsd/article/view/3986. 